\title{
MODELING MERCURY IN POWER PLANT PLUMES
}

Kristen Lohman ${ }^{1}$, Christian Seigneur ${ }^{1}$, Eric Edgerton ${ }^{2}$, and John Jansen ${ }^{3}$

${ }^{1}$ Atmospheric \& Environmental Research, Inc.

2682 Bishop Drive, Suite 120

San Ramon, CA 94583

\author{
${ }^{2}$ Atmospheric Research \& Analysis, Inc. \\ 410 Midenhall Way \\ Cary, NC 27513
}

${ }^{3}$ Southern Company Services

P.O. Box 2641

Birmingham, AL 35291

\section{Supporting Information}

HYSPLIT back-trajectories for the nine plume events 


\section{NOAA HYSPLIT MODEL Backward trajectories ending at 21 UTC 27 Jun 01 EDAS Meteorological Data}

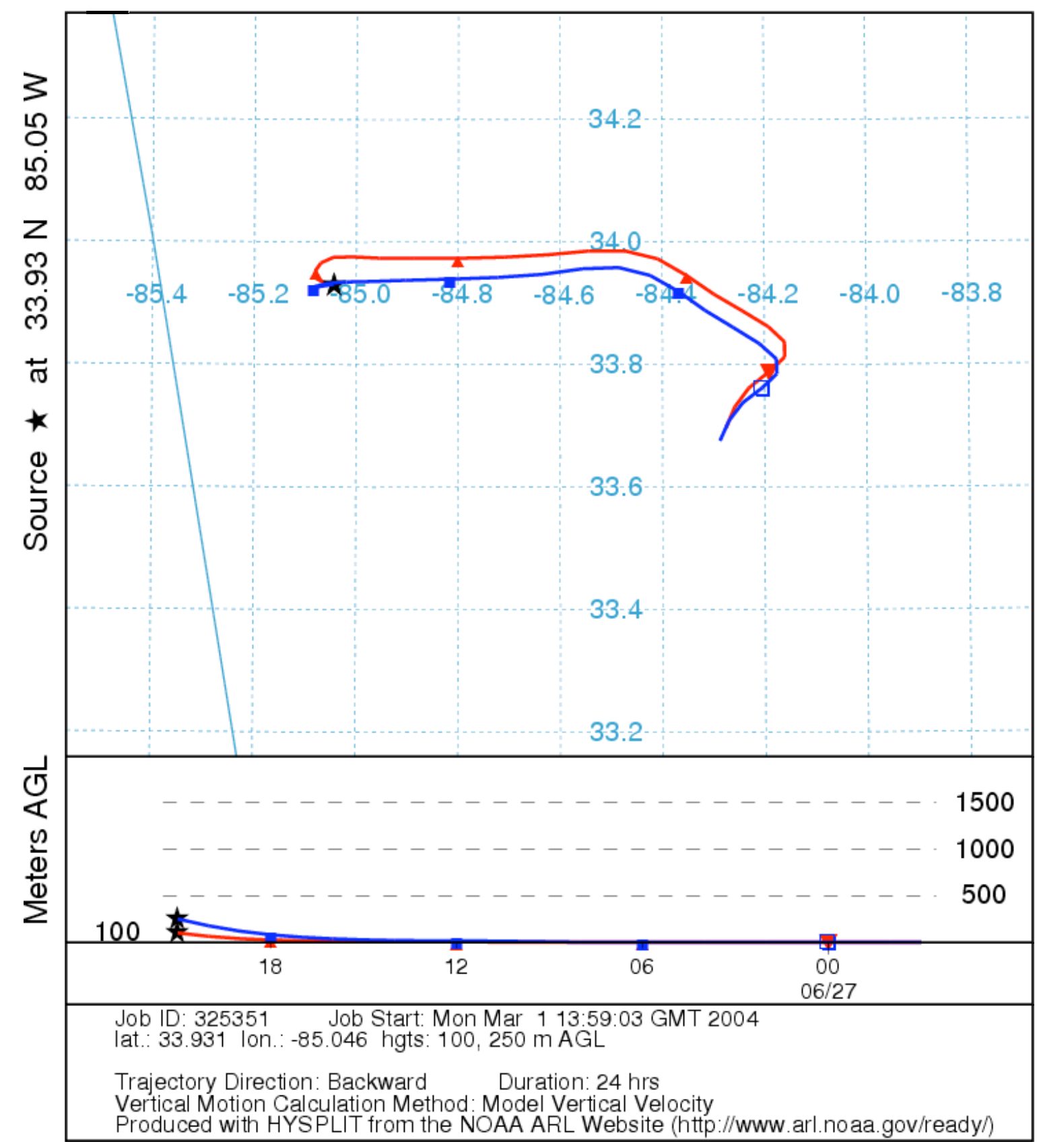

Figure S-1. Trajectory for the Bowen 6/27/01 event. 
NOAA AIR RESOURCES LABORATORY

Backward Trajectories Ending- 14 UTC 20 JUL 01

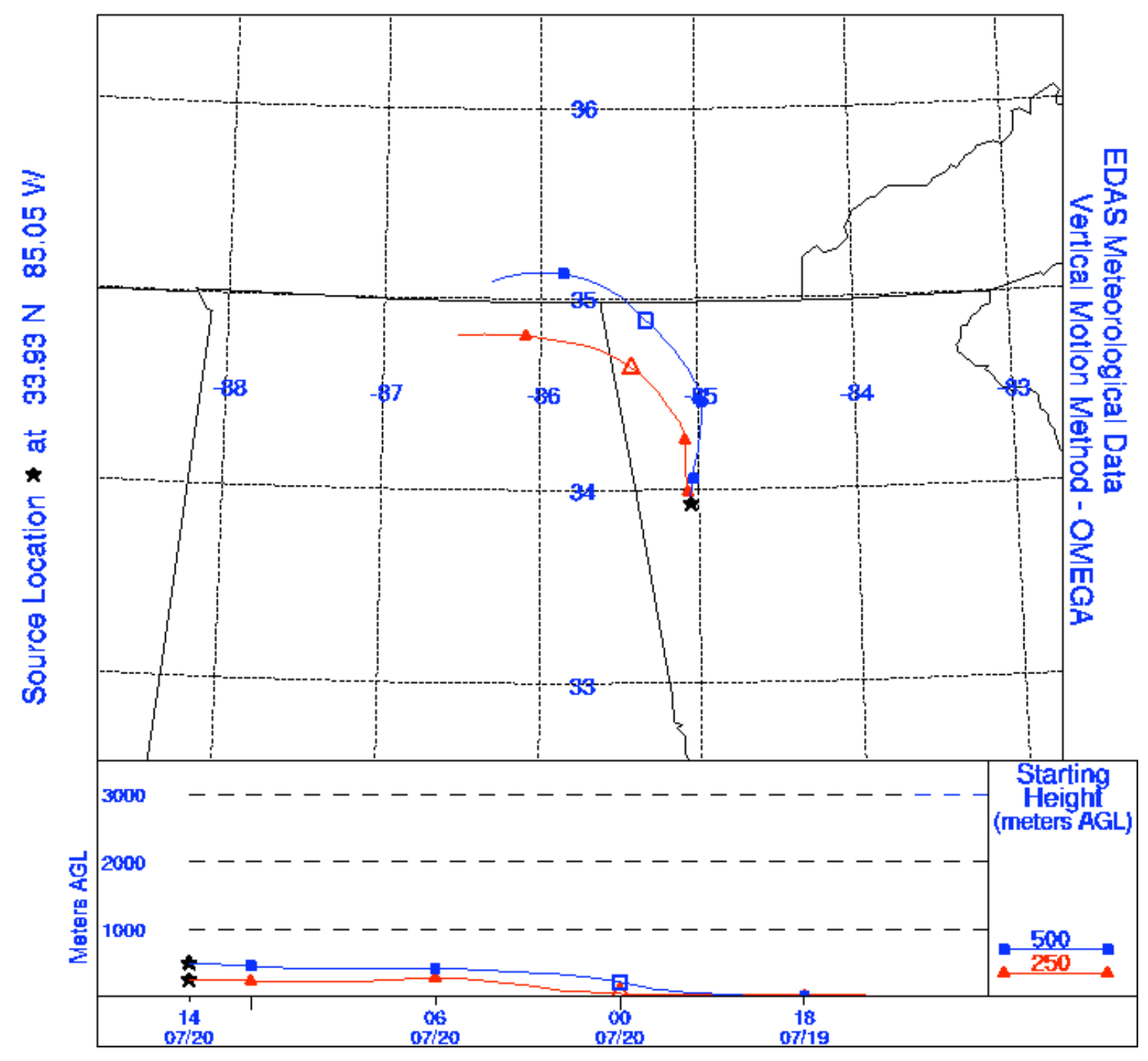

Figure S-2. Trajectory for the Bowen 7/20/01 event. 
NATIONAL OCEANIC ATMOSPHERIC ADMINISTRATION Backward trajectories ending at 17 UTC 07 Dec 01

EDAS Meteorological Data

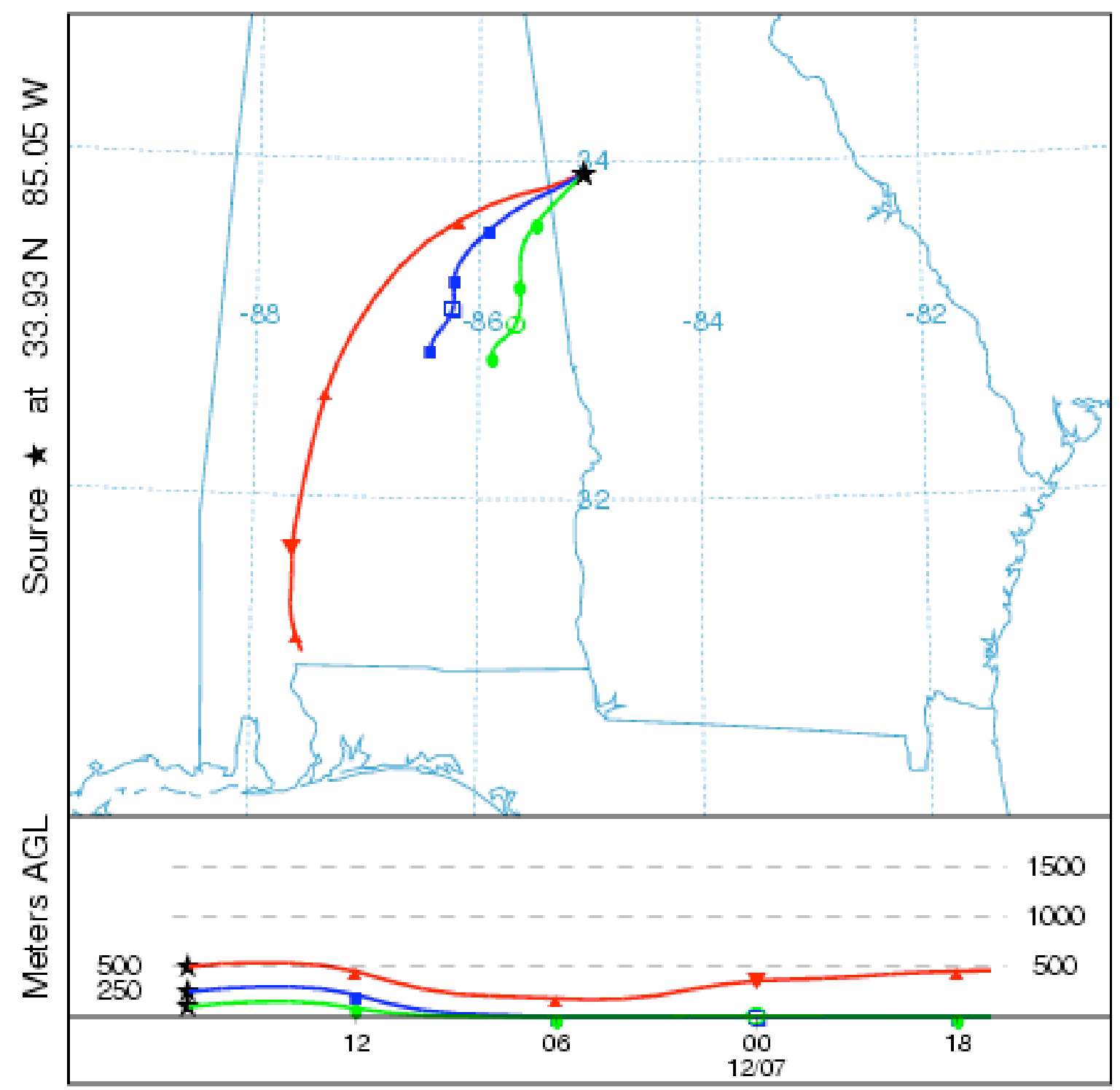

Figure S-3. Trajectory for the Gaston 12/7/01 event 


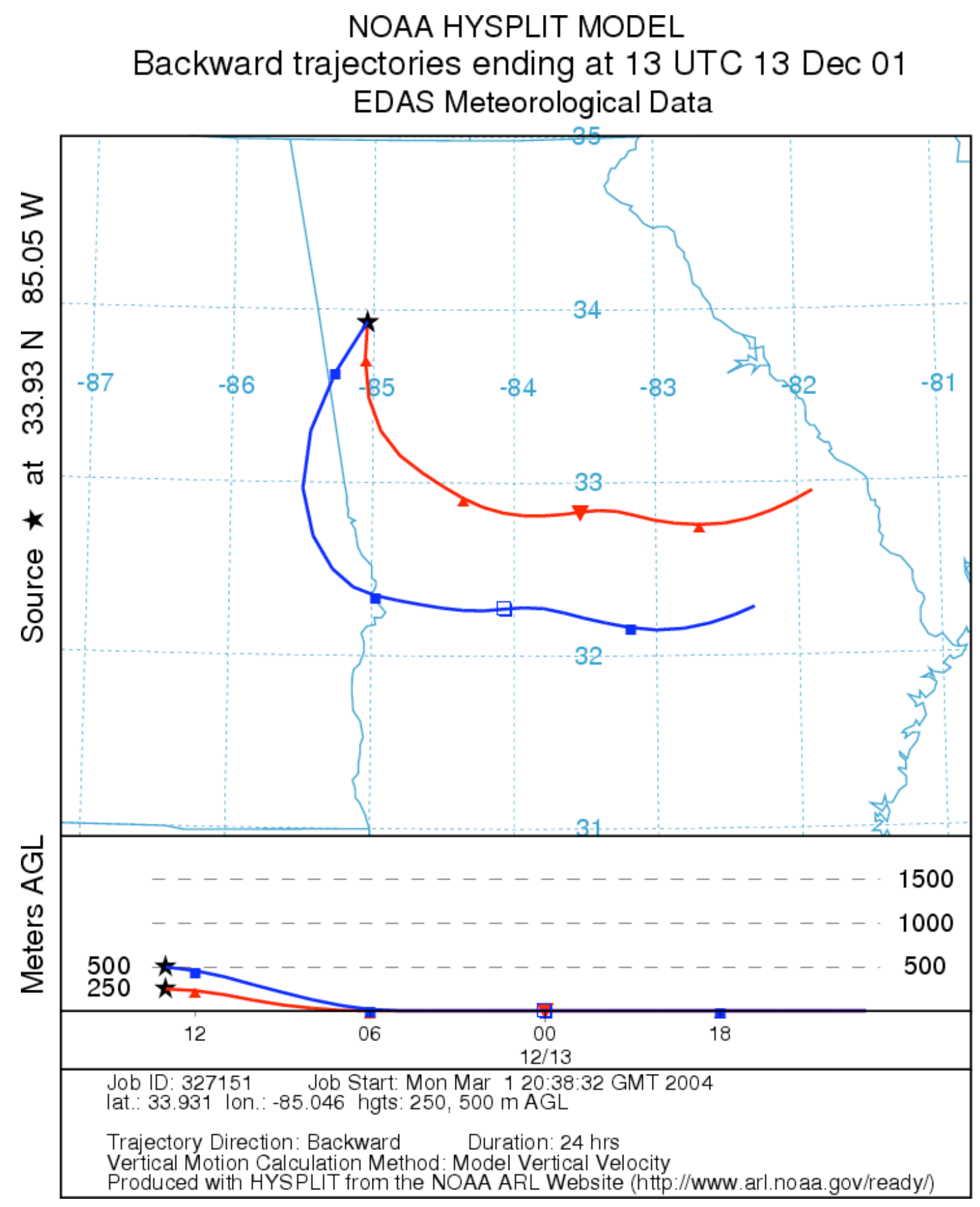

Figure S-4. Trajectory for the Wansley 12/13/01 event. 
NATIONAL OCEANIC ATMOSPHERIC ADMINISTRATION Backward trajectories ending at 00 UTC 30 Dec 01

EDAS Meteorological Data

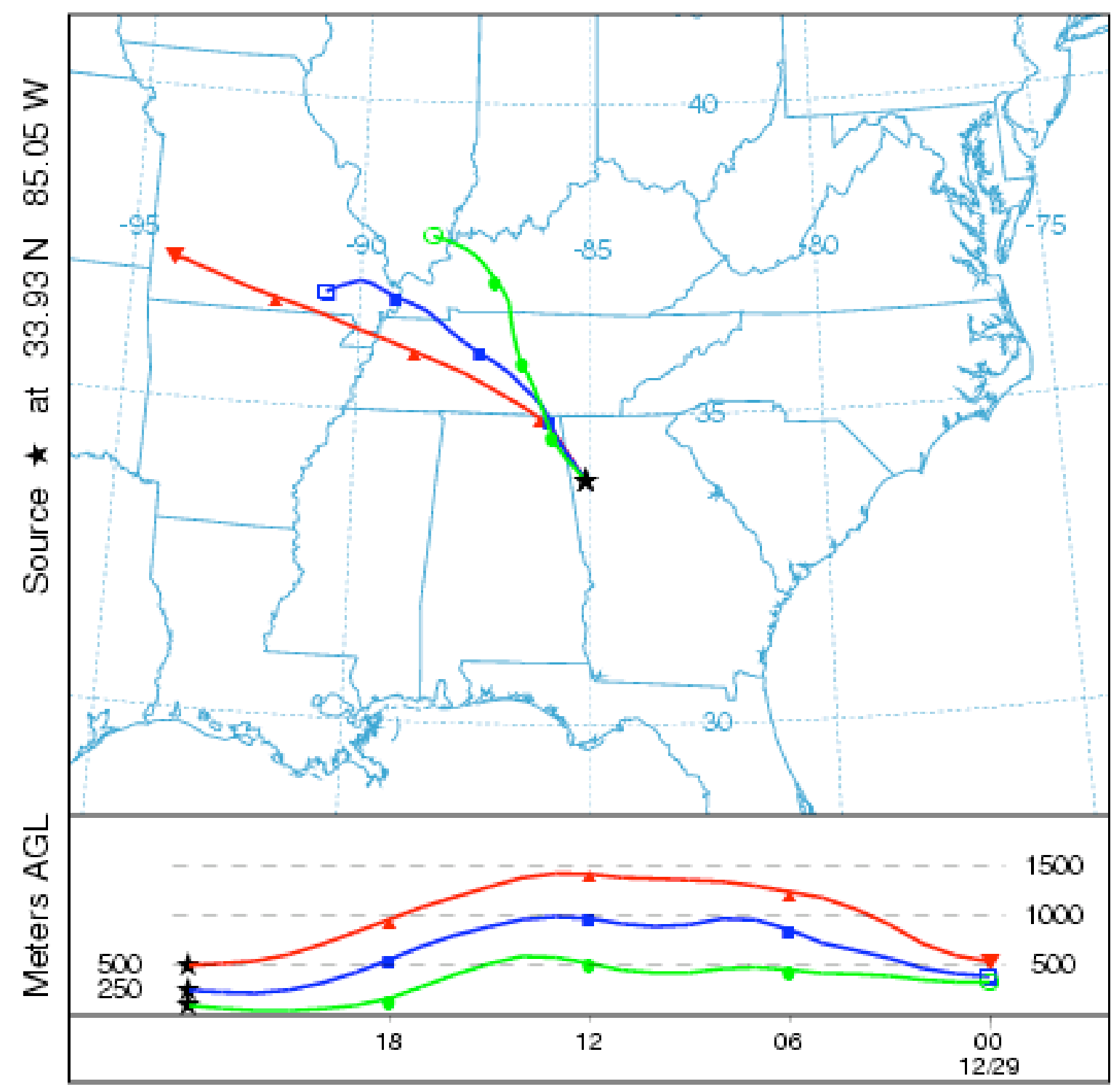

Figure S-5. Trajectory for the Hammond 12/29/01 event. 


\section{NOAA HYSPLIT MODEL Backward trajectories ending at 04 UTC 09 Feb 02 EDAS Meteorological Data}

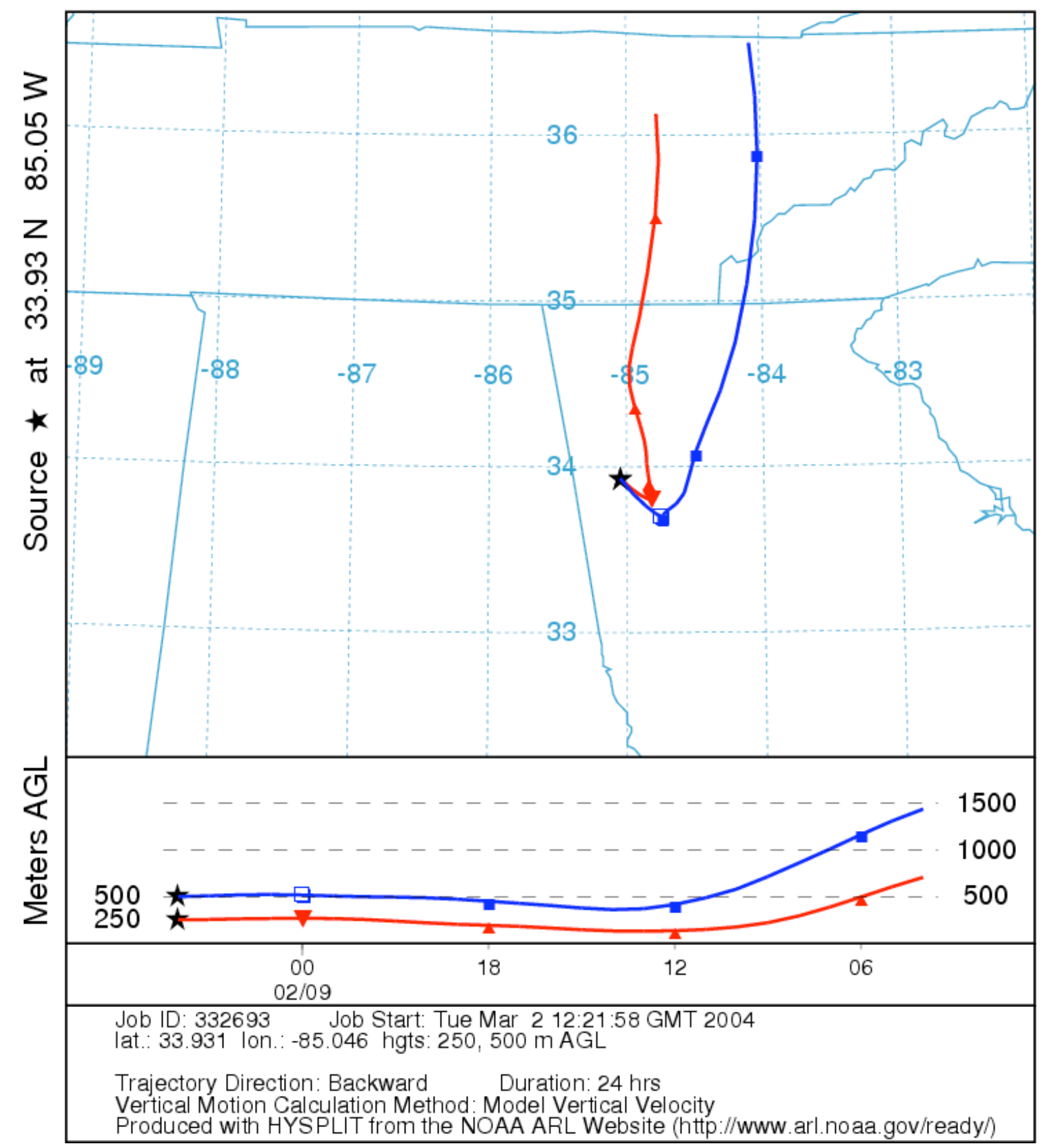

Figure S-6. Trajectory of the Bowen 2/9/02 event 
NATIONAL OCEANIC ATMOSPHERIC ADMINISTRATION Backward trajectories ending at 00 UTC 30 Dec 01 EDAS Meteorological Data

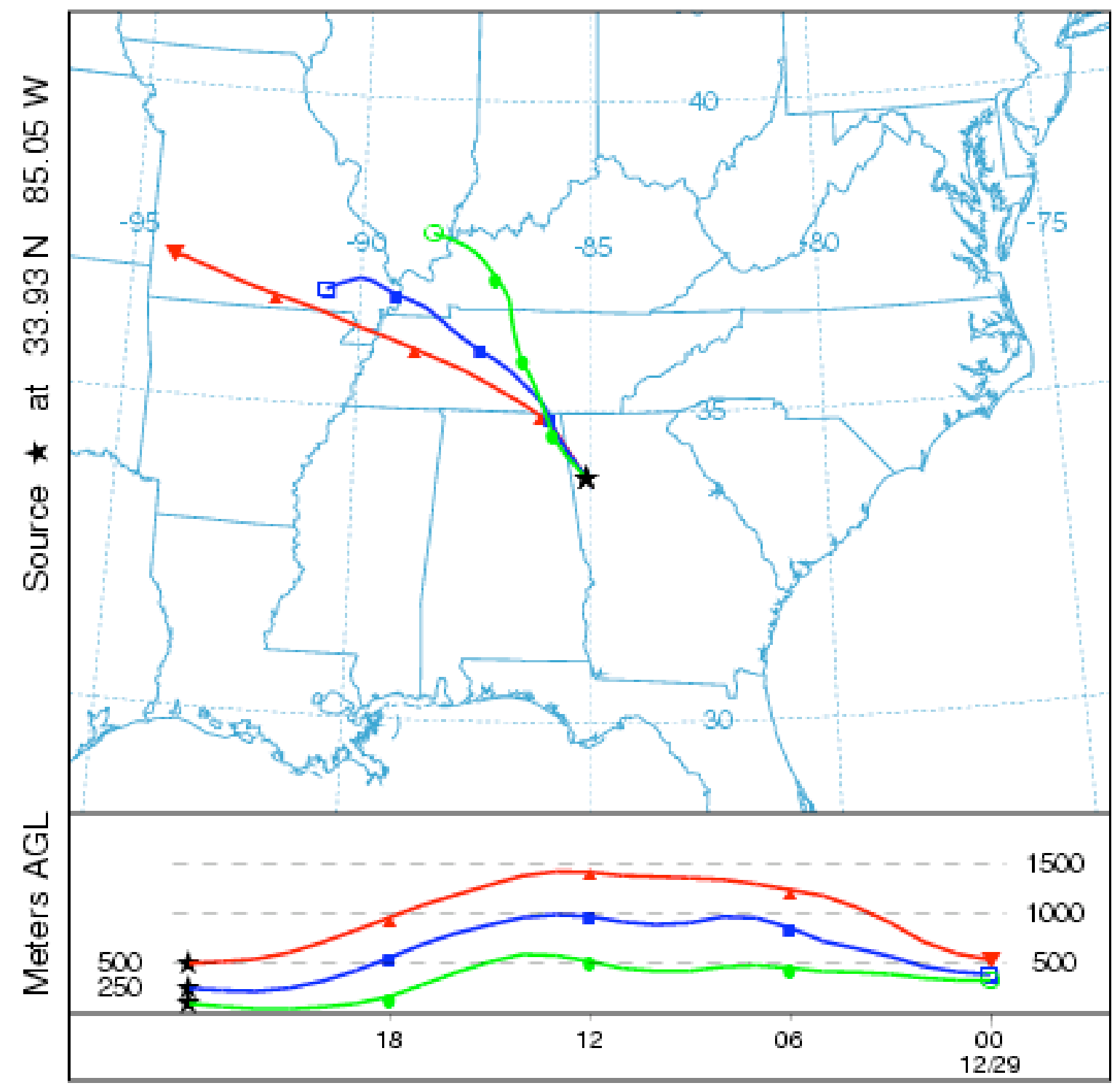

Figure S-7. Trajectory for the Bowen 06/17/02 event. 


\section{NATIONAL OCEANIC ATMOSPHERIC ADMINISTRATION Backward trajectories ending at 22 UTC 05 Jul 02 EDAS Meteorological Data}

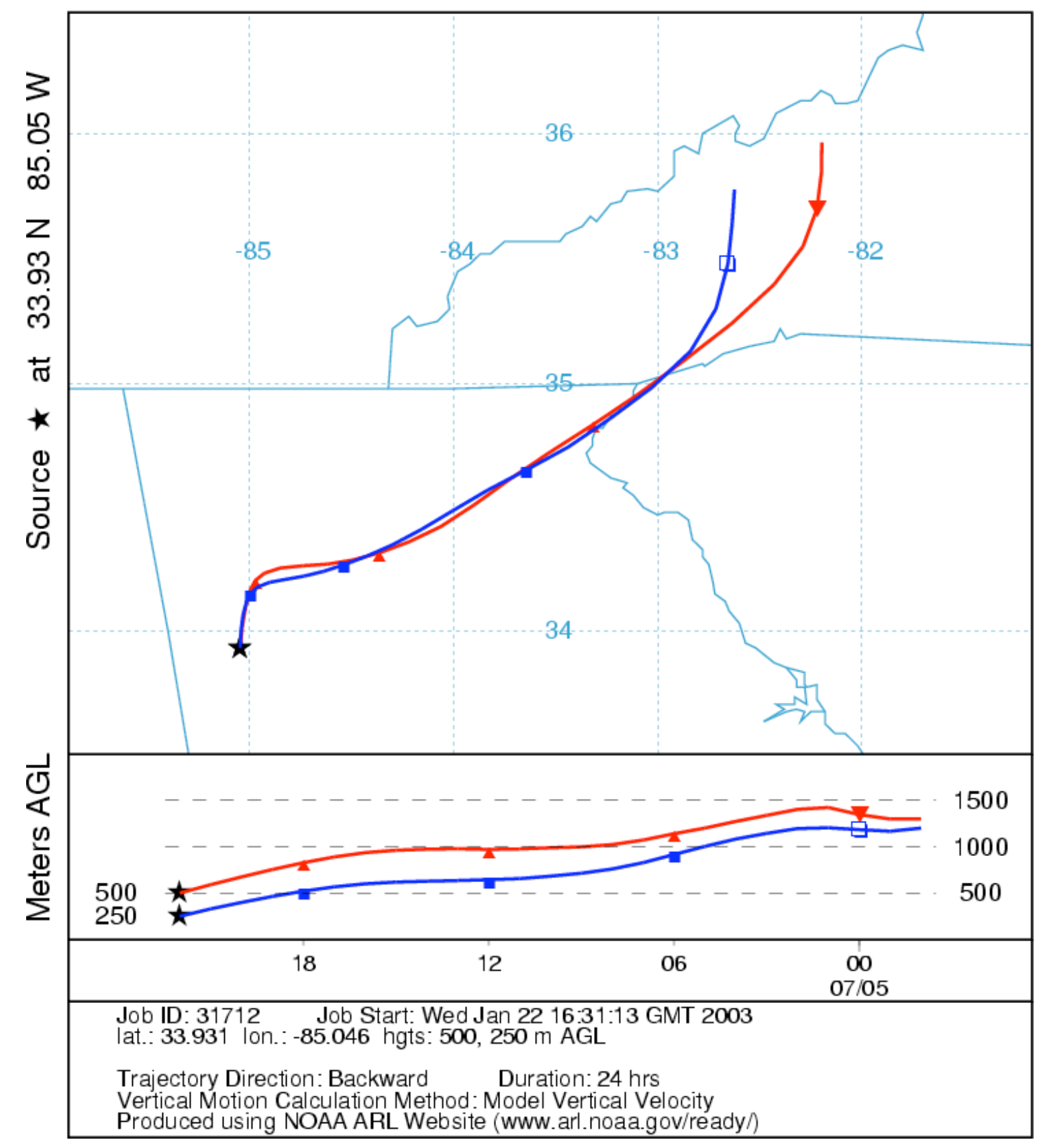

Figure S-8. Trajectory for the Bowen 07/05/02 event. 


\section{NATIONAL OCEANIC ATMOSPHERIC ADMINISTRATION Backward trajectories ending at 20 UTC 21 Jul 02 EDAS Meteorological Data}

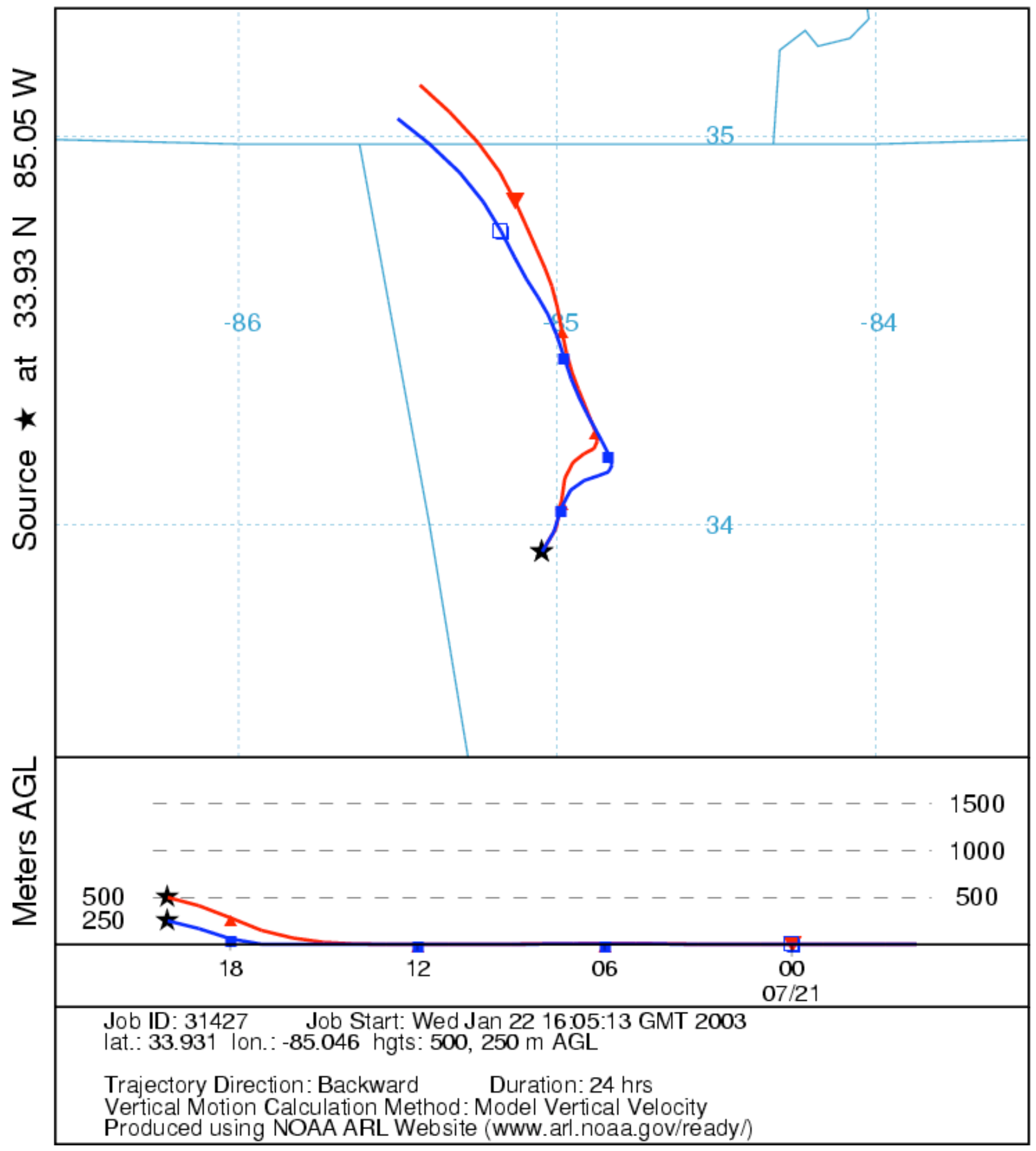

Figure S-9. Trajectory for the Bowen 7/21/02 event. 